\title{
Errors in daily ablation measurements in northern Greenland, 1993-94, and their implications for glacier climate studies
}

\author{
Roger J. Braithwaite, ${ }^{1}$ Thomas Konzelmann, ${ }^{2}$ Christoph Marty, ${ }^{2}$ Ole B. Olesen ${ }^{3}$ \\ ${ }^{1}$ Department of Geography, University of Manchester, Manchester M13 9PL, England \\ ${ }^{2}$ Department of Geography, Swiss Federal Institute of Technology, CH-8057 Zürich, Switzerland \\ ${ }^{3}$ The Geological Survey of Denmark and Greenland, DK-2400 Copenhagen.NV, Denmark
}

\begin{abstract}
Ablation-climate studies were made at two locations in northern Greenland in the summers of 1993 and 1994, respectively. Daily ablation was measured at ten stakes within a small area, and the data were compared with each other to detect gross errors. For example, high standard deviations for data taken on the same day, or low correlations between data series at different stakes, indicate erroneous data. After discarding data for one stake in 1993 and two stakes in 1994, random errors in daily ablation data for individual stakes are $\pm 5 \mathrm{~kg} \mathrm{~m}^{-2} \mathrm{~d}^{-1}$, which is further reduced to only about $\pm 2 \mathrm{~kg} \mathrm{~m}^{-2} \mathrm{~d}^{-1}$ by averaging over eight or nine stakes. Random errors in calculated energy balances using the present ablation data are much lower than found in earlier studies in West Greenland where ablation was only measured on three stakes without any attempt to detect gross errors. Aside from day-to-day errors, there are $\pm 10 \%$ differences in mean ablation at different stakes, which are probably caused by small-scale variations in surface albedo. Such interstake differences give a $\pm 10 \%$ uncertainty in positive degree-day factors, which are $9.8 \pm 0.9$ and $5.9 \pm 0.6 \mathrm{~kg} \mathrm{~m}^{2} \mathrm{~d}^{1} \mathrm{deg}^{1}{ }^{1}$ for the two sites.
\end{abstract}

\section{NOTATION}

$a_{i t} \quad$ Measured ablation at stake $i$ and day $t$

$a_{\text {.t }} \quad$ Average ablation for $M$ stakes on day $t$

$e_{i t}$ Random error

$M \quad$ Number of stakes

$N \quad$ Number of days

$R$ Product-moment correlation coefficient

$S_{\mathrm{e}} \quad$ Standard deviation (S.D.) of error

$S_{\text {.t }} \quad$ S.D. of measured ablation for $M$ stakes on day $t$

$S_{i} \quad \quad$ S.D. of measured ablation for $N$ days at stake $i$

$S_{x} \quad$ S.D. of true ablation for $N$ days

$x_{t} \quad$ True ablation for day $t$

$y_{t} \quad$ Any time series

\section{INTRODUCTION}

The most common way to evaluate ice ablation $\left(\mathrm{kg} \mathrm{m}^{-2}\right)$ is to measure the surface lowering $(\mathrm{m})$ relative to an ablation stake and to multiply the surface lowering by the density of glacier ice $\left(900 \mathrm{~kg} \mathrm{~m}^{-3}\right)$.

Bauer (1961) discussed annual net ablation measurements with six stakes at a single site in Greenland and interpreted differences between stakes as errors. His error standard deviation was $\pm 230 \mathrm{~kg} \mathrm{~m}^{-2} \mathrm{a}^{-1}$, or $\pm 15 \%$ of the annual ablation. Generally similar errors of \pm 200 to $\pm 400 \mathrm{~kg} \mathrm{~m}^{-2} \mathrm{a}^{-1}$ have been reported for annual balances (Lliboutry, 1974; Reynaud and others, 1986; Braithwaite and Olesen, 1989b) using Lliboutry's linear model, and a similar error of \pm 200 to $\pm 250 \mathrm{~kg} \mathrm{~m}^{-2} \mathrm{a}^{-1}$ is given by Cogley and others (1995).

The above errors are much larger than the simple error in measuring from the top of an ablation stake to the ice surface, and presumably reflect gross errors as well as the failure of the data to represent correctly annual ablation in the immediate surroundings of the stake where they are measured. In the present paper, the term "measurement error" is used in this broader sense. This usage is justified because one assumes (or hopes) that a single ablation measurement represents a certain minimum area around the stake, ranging from about $0.1 \mathrm{~km}^{2}$ on a well-studied glacier (Schytt, 1962) to many $\mathrm{km}^{2}$ in a sparse stake network as in Greenland. Braithwaite and Olesen (1989b) showed that errors in annual ablation data reduce correlations between ablation data and climate variables according to the ratio of error variance to ablation variance.

Short-term variations in ablation (e.g. daily variations) have also been measured as part of energy-balance studies (Ambach, 1963; Müller and Keeler, 1969; Braithwaite and Olesen, 1990). In such cases, one would like the measured ablation to be as accurate as possible so that it can be used as a check on the energy balance, which may not be completely accurate due to measurement errors and various unsatisfied assumptions.

Müller and Keeler (1969) studied errors in short-term ablation measurements in some detail. The main errors in surface lowering are due to ablation hollows, which commonly form around stakes, and to the complex micro-relief of the ice surface. A straight edge on the ice surface at the stake can be used as a datum and gives an error of $\pm 0.005 \mathrm{~m}$ in surface lowering, which can be further reduced to $\pm 0.003 \mathrm{~m}$ by the star ablatograph (Müller and Keeler, 1969). There is a further error, in that the density of the 
glacier surface layer can be less than that of glacier ice (e.g. as low as $500-600 \mathrm{~kg} \mathrm{~m}^{-3}$ ), due to "weathering crust" caused by melting within the top few $\mathrm{cm}$ of the glacier surface layer. Any density changes in this layer are not detected by measurements of surface lowering but are so difficult to measure that most people would regard them as unavoidable.

The effects of errors on daily ablation measurements were investigated at two locations in northern Greenland (Fig. 1) in the summers of 1993 and 1994, respectively. The field studies were part of a 2 year programme on world sealevel changes supported by the European Union. Northern Greenland was chosen as the target because there is little information about ablation in this area except for a qualitative description by Fristrup (1951). The present paper examines the accuracy of daily ablation measurements at the two sites and discusses their implications for glacier climate studies.

\section{THE DATA}

Daily measurements of ablation were made at two locations (Fig. 1) in northern Greenland: at the margin of the Greenland ice sheet in Kronprins Christian Land (KPCL) in 1993, and at the margin of the Hans Tausen Ice Cap (HTIC) in 1994. Locations and periods of measurements are shown in Table 1 where the coordinates were determined by repeated positioning with a hand-held receiver for the global positioning system (GPS).

Previous experience has shown that ablation measurements involve considerable error, and that ablation itself

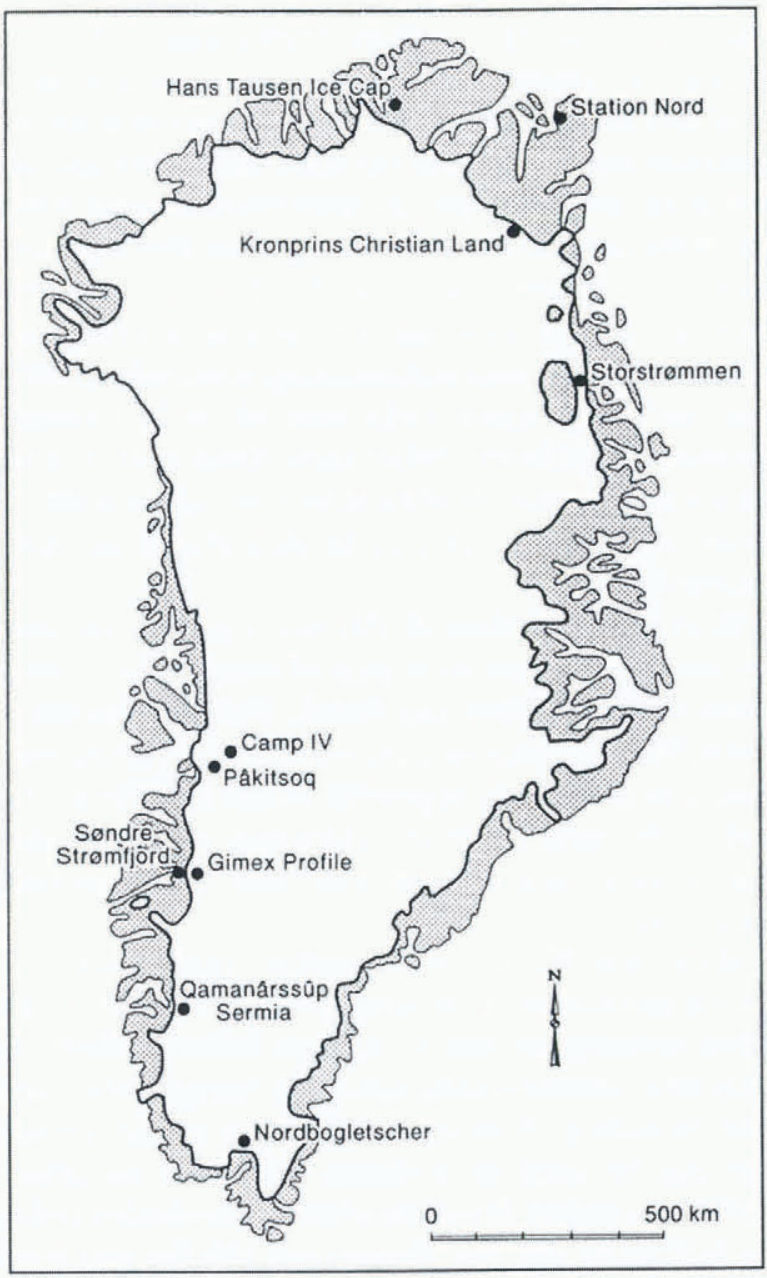

Fig. 1. Location map.
Table 1. Periods of coverage and locations of the two ablationclimate datasets: Kronprins Christian Land (KPCL) and Hans Tausen Ice Cap (HTIC)

KPCL

HTIC
Days

From

To

Elevation (m a.s.l)

Latitude

Longitude

\section{0}

8 July 1993

27 July 1993 380

$79^{\circ} 54^{\prime} 43^{\prime \prime} \mathrm{N}$

$24^{\circ} 04^{\prime} 25^{\prime \prime} \mathrm{W}$
35

2 July 1994

5 August 1994 540

$82^{\circ} 49^{\prime} 26^{\prime \prime} \mathrm{N}$ varies greatly even on a scale of metres, suggesting that many measurements are needed to obtain a representative value for a site (Olesen and Braithwaite, 1989). Ablation in the present study was therefore measured at ten stakes placed within an area of only about $100 \mathrm{~m}^{2}$. The ablationmeasurement sites were located beside climate and radiation stations on the ice, which are a few minutes' walk from field camps established on the tundra. The ten stakes were read daily at close to 1900 UTC (about $1715 \mathrm{~h}$ solar time in KPCL and $1630 \mathrm{~h}$ solar time at HTIC).

Stakes are usually surrounded by an "ablation hollow" of $0.1-0.3 \mathrm{~m}$ diameter, and stake readings are made by the straight-edge method. Differences in successive daily readings are converted into ablation values using an ice density of $900 \mathrm{~kg} \mathrm{~m}^{-3}$. For convenience, ablation is treated in this paper as positive rather than negative, as recommended by Anonymous (1969).

An attempt was made to choose the stake sites at random. However, summer melting was already well under way at the start of the KPCL data collection, with well-developed microtopography, melt streams and cryconite holes, so that subconscious bias in avoiding these features cannot be excluded. By contrast, melting had hardly started in 1994 when the HTIC stakes were established, and melt streams and cryconite holes subsequently developed around several stakes.

At both sites, ablation crust was ubiquitous, but an alternation between a white crusty surface and blue ice, as described by Müller and Keeler (1969), was never observed. This suggests that large changes in surface density did not occur in the present cases.

The first data analysis involves calculating the mean and standard deviation of the ten ablation readings for each day. The daily mean represents the best estimate of the true ablation on that day, and the standard deviation expresses the spread of individual readings around this mean, reflecting the effects of measurement errors as well as any small-scale variations in ablation. For KPCL 1993 (Fig. 2), mean ablation was well above zero for the whole 20 day record, while ablation for HTIC 1994 (Fig. 3) was generally lower and approaches zero several times during the 35 day record. However, day-to-day fluctuations in ablation have a similar amplitude in both cases.

For both datasets (Figs 2 and 3 ) the daily standard deviation is usually quite small, i.e. around $\pm 5 \mathrm{~kg} \mathrm{~m}^{-2} \mathrm{~d}^{-1}$ for most days, but there are also days with much larger standard deviations (e.g. well over $\pm 10 \mathrm{~kg} \mathrm{~m}^{-2} \mathrm{~d}^{-1}$. Presumably the former is due to a random process with a fairly small amplitude, while the latter is caused by a larger, more sporadic effect, i.e. "errors" and "mistakes". 


\section{THEORY}

The ablation $a_{i t}$ measured at stake $i$ on day $t$ is not the true ablation, because of measurement errors and the effects of small-scale variations in ablation. It is assumed that the ablation is given by:

$$
a_{i t}=x_{t}+e_{i t}
$$

where $x_{l}$ is the true ablation for the day, and $e_{i t}$ is a random error. It is assumed here that there are no real differences between stakes, and that any apparent differences are due to the statistical sampling of the error term.

In principle, Equation (1) is not solvable, because it involves two unknown quantities $x_{t}$ and $e_{i t}$. However, with a large number of stakes $(M)$ within a small area, the errors can be assumed to average out, and the true ablation is approximately equal to the average ablation $a_{. t}$ for the $M$ stakes on any particular day:

$$
x_{t} \approx a_{. t}=(1 / M) \sum_{i=1}^{i=M} a_{i t} .
$$

It is assumed that the error $e_{i t}$ has zero mean for $M$ stakes, is uncorrelated with the true ablation $x_{t}$, and has the same standard deviation $S_{\mathrm{e}}$ for both time and space variations. The standard deviation of the error is then equal to the standard deviation $S_{. t}$ of the ablation for the $M$ stakes:

$$
S_{\mathrm{e}}{ }^{2}=S_{. t}{ }^{2}=(1 / M-1) \sum_{i=1}^{i=M}\left(a_{i t}-a_{. t}\right)^{2} .
$$

Under the same assumptions, the standard deviation $S_{i}$. of ablation time series for $N$ days is:

$$
S_{i .}{ }^{2}=S_{x}{ }^{2}+S_{\mathrm{e}}{ }^{2}
$$

where $S_{x}$ is the standard deviation of true ablation $x_{t}$ for $N$ days. The correlation coefficient $R\left(a_{i t}, y_{t}\right)$ between measured ablation and any time series $y_{t}$ is:

$$
R\left(a_{i t}, y_{t}\right)=\left(S_{x} / S_{i .}\right) R\left(x_{t}, y_{t}\right)
$$

where $R\left(x_{t}, y_{t}\right)$ is the correlation coefficient between true ablation and the time series. As $S_{x} / S_{i}$. must be less than unity, Equation (5) means that ablation errors reduce correlations between measured ablation and other variables. In the particular case where $y_{t}=x_{t}$, the correlation coefficient on the righthand side of Equation(5) is unity, and

$$
R\left(a_{i t}, x_{t}\right)=\left(S_{x} / S_{i}\right) .
$$

This represents the highest correlation that can be found between ablation at any individual stake and any other time series.

Ideally, the random error, as expressed by the standard

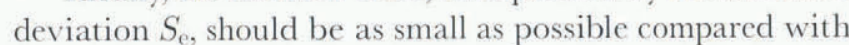
true ablation variations. Otherwise, the presence of large errors affects the interpretation of the ablation measurements. For example, according to Equation (5) with typical values of \pm 5 and $\pm 10 \mathrm{~kg} \mathrm{~m}^{-2} \mathrm{~d}^{-1}$ for $S_{\mathrm{e}}$ and $S_{x}$, correlation coefficients involving measured ablation are reduced by a factor of 0.89 compared with true ablation. For a larger random error (e.g. $S_{\mathrm{e}}=S_{x}= \pm 10 \mathrm{~kg} \mathrm{~m}^{-2} \mathrm{~d}^{-1}$ ), the reduction factor is 0.71. As the percentage of variance that is "explained" by the correlation depends upon the square of the correlation coefficient, i.e. $79 \%$ and $50 \%$ in the two examples here, measurement errors in daily ablation can easily reduce the predictive power of ablation-climate correlations by $20-50 \%$.

Equation (1) assumes that the true ablation is the same at
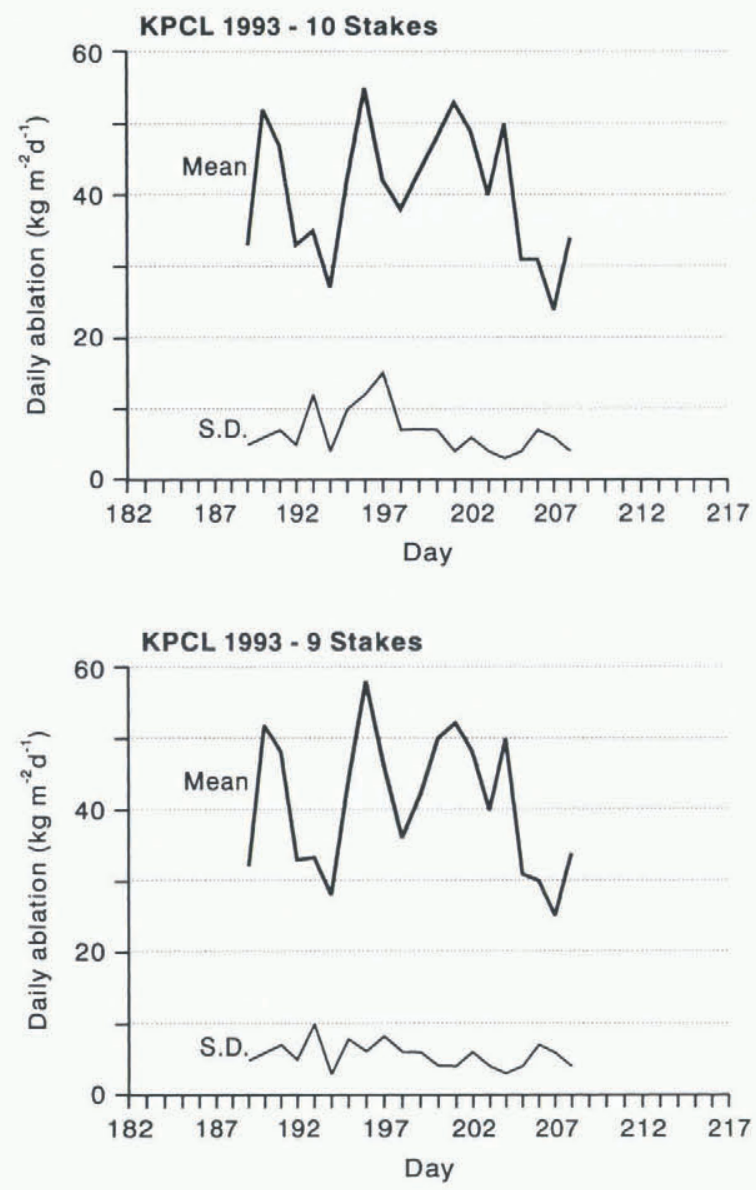

Fig. 2. Mean and standard deviation (S.D.) of daily ablation, 8-27 July 1993 (days 189-208), at KPCL, northern Greenland.
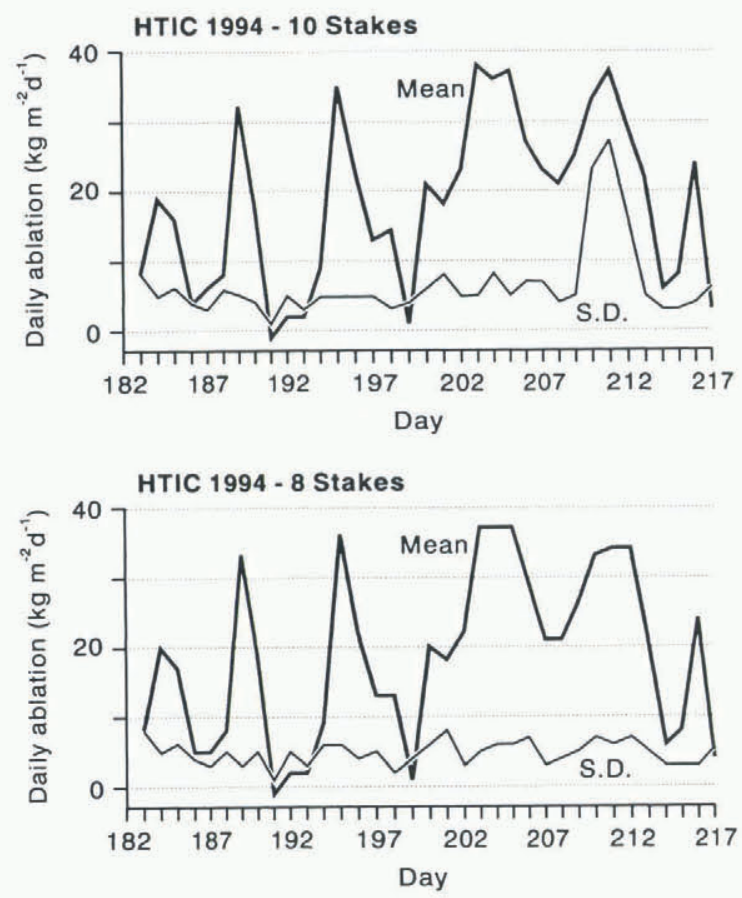

Fig. 3. Mean and standard deviation (S.D.) of daily ablation, 2. July-5 August 1994 (days 183 217), at HTIC, northern Greenland.

all stakes, so that observed differences are due to statistical sampling alone; however, ablation at the different stakes need not be the same. For example, in the linear model:

$$
a_{i t}=x_{t}+z_{i}+e_{i t},
$$

$x_{t}$ and $e_{i t}$ are the same as before, but the new term $z_{i}$ repre- 
sents possible differences in ablation between stakes. This equation was first applied to stake networks by Lliboutry (1974).

\section{MAGNITUDE OF ERRORS}

According to the theory, random errors in ablation measurements should have similar effects for all stakes, and similar effects for all days. This principle can be used for detection of gross errors. For example, the few large values of daily standard deviations in the upper parts of Figures 2 and 3 indicate the operation of something other than a random error, i.e. a relatively large error that is more sporadic.

Correlation coefficients between ablation series at individual stakes and the mean ablation for all stakes (Table 2) are generally similar, as predicted by Equation (6), but there are some cases with very low correlations. For example, stake B in the KPCL 1993 dataset has a correlation coefficient of only 0.35 compared to an average of 0.84 for all ten stakes in Table 2. Re-examination of the data for individual cases shows that anomalous data were collected at this stake on 2 out of 20 days, i.e. with errors of -28 and $-38 \mathrm{~kg} \mathrm{~m}^{-2} \mathrm{~d}^{-1}$, but it is impossible to guess the correct values. Data for stake B were therefore excluded from the dataset, and calculations were repeated for the other nine stakes, raising the average correlation from 0.84 to 0.91 (Table 2). The few large daily standard deviations in the upper part of Figure 2 are also reduced, although variations of mean ablation are little changed (because the effect of the original errors is "diluted").

In the HTIC 1994 dataset, there are low correlation coefficients of 0.61 and 0.68 at stakes B and E compared to a mean of 0.88 for all ten stakes (Table 2). In the case of stake $\mathrm{B}$, there are two large anomalies with similar magnitude and opposite signs, i.e. errors of +48 and $-42 \mathrm{~kg} \mathrm{~m}^{-2} \mathrm{~d}^{-1}$, consistent with a single wildly inaccurate stake reading. At stake $\mathrm{E}$ there are three anomalies, errors of $-46,+66$ and $-43 \mathrm{~kg} \mathrm{~m}^{-2} \mathrm{~d}^{-1}$, which are harder to interpret. Instead of trying to guess the correct data, we excluded stakes B and E from the dataset, and calculations were repeated for the remaining eight stakes, raising the average correlation from 0.88 to 0.94 (Table 2 ). The group of very large standard deviations in the upper part of Figure 3 completely disappears.

In the reduced datasets, errors outside the range $\pm 10 \mathrm{~kg}$ $\mathrm{m}^{-2} \mathrm{~d}^{-1}$ occur with frequencies of only $9 \%$ and $5 \%$, and the

Table 2. Correlation coefficients between the daily ablation at individual stakes and the mean ablation for $\mathcal{N}$ stakes

\begin{tabular}{ccccc}
\hline & \multicolumn{2}{c}{ KPCL 1.993 } & \multicolumn{2}{c}{$\begin{array}{c}\text { HTIC 1994 } \\
(20 d)\end{array}$} \\
Stakes & $N=10$ & $N=9$ & $N=10$ & $N=8$ \\
& & 0.94 & 0.94 & 0.94 \\
A & 0.92 & - & 0.68 & - \\
B & 0.35 & 0.83 & 0.98 & 0.98 \\
C & 0.83 & 0.85 & 0.89 & 0.90 \\
D & 0.84 & 0.92 & 0.61 & - \\
E & 0.90 & 0.91 & 0.95 & 0.95 \\
F & 0.90 & 0.93 & 0.91 & 0.91 \\
G & 0.90 & 0.91 & 0.92 & 0.93 \\
H & 0.90 & 0.96 & 0.94 & 0.94 \\
I & 0.94 & 0.95 & 0.97 & 0.97 \\
J & 0.95 & 0.91 & 0.88 & 0.94 \\
Mean & 0.84 & \pm 0.04 & \pm 0.13 & \pm 0.03 \\
S.D. & \pm 0.18 & & & \\
\hline
\end{tabular}

corresponding error standard deviations are only \pm 6 and $\pm 5 \mathrm{~kg} \mathrm{~m}^{-2} \mathrm{~d}^{-1}$. The accuracy of an individual stake measurement can be taken as the same magnitude.

The true ablation for any day was assumed to be given by the mean ablation at $M$ stakes (Equation (2)), but this involves a sampling error of $S_{\mathrm{e}} / M^{0.5}$, which is $\pm 2 \mathrm{~kg} \mathrm{~m}^{-2} \mathrm{~d}^{-1}$ for eight or nine stakes when $S_{\mathrm{e}}= \pm 6 \mathrm{~kg} \mathrm{~m}^{-2} \mathrm{~d}^{-1}$. The error in mean ablation for any day can be taken as the same magnitude.

\section{DIFFERENCES BETWEEN STAKES}

The mean ablation appears to be different at different stakes (Table 3). The statistical significance of the differences is studied by a two-way analysis of variance (Kreyszig, 1970, p. 274-287) using Equation (7). The resulting sources of variance are shown in Table 4 . As one might expect, the largest source of variance in both cases is the day effect, i.e. the dayto-day change in ablation according to weather. Next largest is the unexplained variance, mainly due to measurement errors, and the smallest is the stake effect, reflecting only small differences between stakes.

According to the F-test (Kreyszig, 1970, p. 277), the differences between days are significantly different at a very low probability level for both samples. The situation for stake differences is less clear: for KPCL 1993 (with 8 by 152 degrees of freedom) the differences are significantly different at $5 \%$ level, but differences are not significant for HTIC 1994 ( 7 by 238 degrees of freedom).

The alternative to a purely statistical treatment is to look for a physical difference between stakes. For example, Konzelmann and Braithwaite (1995) have already noted the

Table 3. Mean daily ablation for individual stakes

\begin{tabular}{ccc}
\hline Stakes & $\begin{array}{c}\text { KPCL } 1993 \\
(20 \mathrm{~d})\end{array}$ & $\begin{array}{c}\text { HTIC 1994 } \\
(35 \mathrm{~d})\end{array}$ \\
& $\mathrm{kg} \mathrm{m}^{-2} \mathrm{~d}^{-1}$ & $\mathrm{~kg} \mathrm{~m}^{-2} \mathrm{~d}^{-1}$ \\
\hline A & 47 & 18 \\
B & - & - \\
C & 45 & 20 \\
D & 42 & 20 \\
E & 40 & - \\
F & 38 & 17 \\
G & 41 & 16 \\
H & 37 & 16 \\
I & 35 & 20 \\
J & 43 & 18 \\
Mean & 41 & \pm 2 \\
S.D. & \pm 4 & 8 \\
M & 9 & \\
\hline
\end{tabular}

Table 4. Sources of variance for daily ablation

\begin{tabular}{|c|c|c|c|c|}
\hline & \multicolumn{2}{|c|}{$K P C L$} & \multicolumn{2}{|c|}{ HTIC } \\
\hline Days & \multicolumn{2}{|l|}{20} & \multicolumn{2}{|c|}{35} \\
\hline Year & \multicolumn{2}{|c|}{1993} & \multicolumn{2}{|c|}{1994} \\
\hline \multirow[t]{2}{*}{ Stakes } & \multicolumn{2}{|l|}{9} & \multicolumn{2}{|c|}{8} \\
\hline & Sum of squares & $\begin{array}{l}\text { Degrees of } \\
\text { freedom }\end{array}$ & Sum of squares & $\begin{array}{l}\text { Degrees of } \\
\text { freedom }\end{array}$ \\
\hline Stake effect & $2173(10 \%)$ & 19 & $878(2 \%)$ & 34 \\
\hline Day effect & $15880(73 \%)$ & 8 & $39630(86 \%)$ & 7 \\
\hline Unexplained & $3650 \quad(17 \%)$ & 152 & $5545(12 \%)$ & 238 \\
\hline Total & $21703(100 \%)$ & 179 & $46122(100 \%$ & 279 \\
\hline
\end{tabular}


Table 5. Mean and standard deviation (S.D.) of ablation for stakes classified as "dark" and "light"

\begin{tabular}{|c|c|c|c|c|c|c|}
\hline & \multicolumn{3}{|c|}{$\begin{array}{c}\text { KPCL } \\
\text { (nine stakes) }\end{array}$} & \multicolumn{3}{|c|}{$\begin{array}{c}\text { HTIC } \\
\text { (eight stakes) }\end{array}$} \\
\hline & Mean & S.D. & $M$ & Mean & S.D. & $M$ \\
\hline & \multicolumn{3}{|c|}{$\mathrm{kg} \mathrm{m}^{-2} \mathrm{~d}^{-1} \mathrm{~kg} \mathrm{~m}^{-2} \mathrm{~d}^{-1}$} & \multicolumn{3}{|c|}{$\mathrm{kg} \mathrm{m}^{-2} \mathrm{~d}^{-1} \mathrm{~kg} \mathrm{~m}^{-2} \mathrm{~d}^{-1}$} \\
\hline "Dark" & 44 & \pm 2 & 4 & 19 & \pm 1 & 4 \\
\hline "Light" & 39 & \pm 3 & 5 & 17 & \pm 2 & 4 \\
\hline All stakes & 41 & \pm 4 & 9 & 18 & \pm 2 & 8 \\
\hline
\end{tabular}

significant difference in ablation at the different stakes for KPCL 1993 and explained it by small-scale variations in albedo, causing differences in absorbed shortwave radiation.

It is not possible to measure albedo exactly at a stake, because the stake and albedometer interfere with each other, but albedo was assessed indirectly by subjectively classifying the immediate surroundings of each stake as "dark" or "light". In both cases, the mean ablation for "dark" stakes is higher than for "light" stakes (Table 5). The range in measured albedo values is 0.1 in the general area of the KPCL 1993 stakes (Konzelmann and Braithwaite, 1995) and is similar for HTIC 1994. This refers to the difference between minimum and maximum albedo, and the difference between "light" and "dark" stakes must be smaller (e.g. of the order of 0.05). For KPCL 1993 the mean global radiation is $317 \mathrm{~W} \mathrm{~m}^{2}$, and an albedo difference of 0.05 gives a difference of $16 \mathrm{Wm}$ ${ }^{2}$ in ablation energy, equivalent to an ablation difference of $4.1 \mathrm{~kg} \mathrm{~m}^{-2} \mathrm{~d}^{-1}$. For HTIC 1994 the mean global radiation is only $223 \mathrm{~W} \mathrm{~m}^{-2}$, giving an ablation difference of only $2.9 \mathrm{~kg} \mathrm{~m}^{2} \mathrm{~d}^{1}$. These figures are in rough agreement with the ablation differences in Table 5, supporting the notion that (1) mean ablation differences between close stakes are partly caused by albedo variations, and (2) the interstake ablation differences for HTIC 1994 are less than those for KPCL 1993 because of lower global radiation in 1994.

\section{IMPLICATIONS FOR DEGREE-DAY MODELLING}

The validity of degree-day modelling rests partly upon a relatively high correlation between ablation and air temperature (Braithwaite and Olesen, 1989a). However, the correlation coefficients in Table 2 suggest that very low correlations can occur with data from single stakes. For example, daily ablation at stake B for KPCL 1993 would have a low correlation with air temperature (or any other climate element) due to the effects of errors, and one would mistakenly infer only a weak correlation between ablation and temperature (or any other climate variable).

Measured ablation in West Greenland has been used to estimate positive degree-day factors (Braithwaite and Olesen, 1989a) that are then applied to the whole Greenland ice sheet (Huybrechts and others, 1991). For these purposes, ablation data should be as accurate as possible so that degree-day factors are not unduly affected by errors.

Positive degree-day factors are calculated for the two datasets by dividing the mean ablation values in Table 3 by the corresponding mean of positive temperatures for the datasets. These are $4.18^{\circ} \mathrm{C}$ for KPCL 1993 and $3.10^{\circ} \mathrm{C}$ for HTIC 1994, based on hourly air temperatures recorded by
Table 6. Positive degree-day factors calculated for individual stakes

\begin{tabular}{ccc}
\hline Stake & $\begin{array}{c}\text { KPCL l993 } \\
(20 d)\end{array}$ & $\begin{array}{c}\text { HTIC 1994 } \\
(35 d)\end{array}$ \\
& $\mathrm{kg} \mathrm{m}^{-2} \mathrm{~d}^{-1} \mathrm{deg}^{-1}$ & $\mathrm{~kg} \mathrm{~m}^{-2} \mathrm{~d}^{-1} \mathrm{deg}^{-1}$ \\
\hline A & 11.1 & 5.8 \\
B & - & - \\
C & 10.8 & 6.5 \\
D & 10.0 & 6.5 \\
E & 9.6 & - \\
F & 9.1 & 5.5 \\
G & 9.8 & 5.2 \\
H & 8.9 & 5.1 \\
I & 8.4 & 6.5 \\
J & 10.3 & 5.9 \\
Mean & 9.8 & \pm 0.6 \\
S.D. & \pm 0.9 & \\
\hline
\end{tabular}

data loggers (at about $2 \mathrm{~m}$ over the glacier surface) only a few metres from where the ablation stakes were measured.

The resulting positive degree-day factors (Table 6) show not only a clear difference between the two sites, but also a substantial variation of about $\pm 10 \%$ between stakes at the same site. As different degree-day factors can be calculated from the ablation for "dark" and "light" stakes (Table 5), it can be concluded that small-scale albedo differences partly explain these interstake variations in positive degree-day factors. However, the difference in mean degree-day factors at the two sites ( 9.8 and $5.9 \mathrm{~kg} \mathrm{~m}^{-2} \mathrm{~d}^{-1} \mathrm{deg}^{-1}$ ) is too large to be caused by errors in ablation measurements. Variations in positive degree-day factors at other sites in Greenland (Braithwaite, 1995, fig. 3) are also too large to be explained by a $\pm 10 \%$ error in ablation measurements.

\section{IMPLICATIONS FOR ENERGY-BALANCE MODELLING}

Another important reason for measuring ablation is to check the accuracy of energy-balance measurements (Streten and Wendler, 1968; Müller and Keeler, 1969; Föhn, 1973; Wendler and Weller, 1974; Munro, 1990), or energybalance models (Escher-Vetter, 1985; Hay and Fitzharris, 1988; Braithwaite and Olesen, 1990).

Each component of the energy balance is measured or estimated as accurately as possible, but due to various errors the sources and sinks do not exactly balance. This effect is expressed by the standard deviation of the "error" terms in Table 6 for West Greenland (Braithwaite and Olesen, 1990) and for the two sites in northern Greenland. The latter are documented in a separate paper (Braithwaite and others, 1998), but the KPCL 1993 values here are essentially based on Konzelmann and Braithwaite (1995) with recalculation of the turbulent fluxes using log-linear profiles and a larger surface roughness.

Small mean errors in energy-balance modelling are easily achieved by suitable choices of parameters in the model, and can always be reduced to zero by suitable "model tuning". However, the standard deviations of the errors in Table 7 do express the overall accuracy of the energy balance. It is noteworthy that the energy balance is much more accurate at the two northern Greenland sites with a 
Table 7. Error in calculated energy balance at four sites in Greenland: Nordbogletscher (NBG), Qamanârssûp sermia $(Q A M)$, Kronprins Christian Land (KPCL) and Hans Tausen Ice Cap (HTIC)

\begin{tabular}{lrrrr}
\hline & NBG & QAM & KPLC & HTIC \\
\hline Latitude $\left({ }^{\circ} \mathrm{N}\right)$ & 61 & 64 & 80 & 83 \\
Days & 415 & 512 & 20 & 35 \\
Stakes & 3 & 3 & 10 & 10 \\
Error $\left(\mathrm{W} \mathrm{m}^{-2}\right)$ & \pm 53 & \pm 73 & \pm 18 & \pm 20 \\
& & & & \\
\hline
\end{tabular}

standard deviation of only $\pm 20 \mathrm{~W} \mathrm{~m}^{-2}$, equivalent to about $\pm 5 \mathrm{~kg} \mathrm{~m}^{-2} \mathrm{~d}^{-1}$. This is comparable to the reduced error in the ablation measurements $\left( \pm 2 \mathrm{~kg} \mathrm{~m}^{-2} \mathrm{~d}^{-1}\right)$, suggesting that improved ablation measurements do partly contribute to a more accurate energy balance than in the West Greenland studies, where ablation was only measured on three stakes without any effort to detect and eliminate gross errors.

\section{CONCLUSIONS}

Measurement errors in glacier climate studies can be reduced by measuring daily ablation at many stakes close together (e.g. at least ten stakes within a small area) and comparing the data to detect gross errors. For example, a high standard deviation for ablation data taken on the same day, or a low correlation between data series at different stakes, indicates erroneous data. These data should be discarded if it is too late to repeat the measurements. In the two cases studied, random errors in daily ablation data for individual stakes are about $\pm 5 \mathrm{~kg} \mathrm{~m}^{-2} \mathrm{~d}^{-1}$ after discarding erroneous data. The error is further reduced to only about $\pm 2 \mathrm{~kg} \mathrm{~m}^{-2} \mathrm{~d}^{-1}$ by averaging over eight or nine stakes.

Random errors in calculated energy balances using the present ablation data are much lower than found in earlier studies in West Greenland where ablation was only measured on three stakes without any attempt to detect and eliminate gross errors.

Aside from day-to-day errors, there are $\pm 10 \%$ differences in mean ablation at different stakes, which are probably caused by small-scale variations in surface albedo. Such interstake differences give a $\pm 10 \%$ uncertainty in the positive degree-day factors, which are $9.8 \pm 0.9$ and $5.9 \pm 0.6 \mathrm{~kg} \mathrm{~m}^{-2} \mathrm{~d}^{-1} \mathrm{deg}^{-1}$ for the two sites.

\section{ACKNOWLEDGEMENTS}

This paper is published by permission of the Geological Survey of Denmark and Greenland (GEUS, formerly GGU). Fieldwork in both 1993 and 1994 was supported by the European Union under contract number EV5V-CT910051, and co-ordinated by the Climate Research Unit, University of East Anglia, U.K. Additional support for the 1994 work on the HTIC was provided by the Nordic Council under a contract to N. Reeh, Danish Polar Centre, Copenhagen. Logistic support in both years was supplied by
GGU's base camp at Centrum Sø, KPCL, led by GGU Statsgeolog N. Henriksen.

\section{REFERENGES}

Ambach, W. 1963. Untersuchungen zum Energieumsatz in der Ablationszone des grönländischen Inlandeises (Camp IV-EGIG, 69 $40^{\prime} 05^{\prime \prime} \mathrm{N}$, $49^{\circ} 37^{\prime} 58^{\prime \prime}$ W). Medd. Gronl., 174(4).

Anonymous. 1969. Mass-balance terms. f. Glaciol, 8 8 (52), 3-7.

Bauer, A. 1961. Précision des mesures d'ablation. International Association of Scientific Hydrology Publication 54 (General Assembly of Helsinki 1960-Snow and Ice), 136-143.

Braithwaite, R. J. 1995. Positive degree-day factors for ablation on the Greenland ice sheet studied by energy-balance modelling. 7. Glaciol., $41(137), 153-160$.

Braithwaite, R. J. and O. B. Olesen. 1989a. Calculation of glacier ablation from air temperature, West Greenland. In Oerlemans, J., ed. Glacier fluctuations and climatic change. Dordrecht, etc., Kluwer Academic Publishers. 219233.

Braithwaite, R.J. and O. B. Olesen. 1989b. Detection of climate signal by inter-stake correlations of annual ablation data, Qamanârssûp sermia, West Greenland. J. Glaciol., 35 (120), 253-259.

Braithwaite. R. J. and O. B. Olesen. 1990. A simple energy-balance model to calculate ice ablation at the margin of the Greenland ice sheet. 7 . Glaciol., 36(123), 222-228.

Braithwaite, R.J., T. Konzelmann, C. Marty and O. B. Olesen. 1998 Reconnaisance study of glacier energy balance in North Greenland, 1993-94. 7. Glaciol., 44(147), 239247.

Cogley, J. G., W. P. Adams, M. A. Ecclestone, F. Jung-Rothenhäusler and C. S. L. Ommanney. 1995. Mass balance of Axel Heiberg Island glaciers, 1960-1991: a reassessment and discussion. Saskatoon, Sask., Environment Canada. National Hydrology Research Institute. (NHRI Science Report 6.)

Escher-Vetter, H. 1985. Energy balance calculations for the ablation period 1982 at Vernagtferner, Oetztal Alps. Ann. Glaciol., 6, 158-160.

Föhn. P. M. B. 1973. Short-term snow melt and ablation derived from heatand mass-balance measurements. J. Glaciol., 12 (65), 275- 289.

Fristrup, B. 1951. Climate and glaciology of Peary Land, North Greenland. International Association of Scientific Hydrology Publication 32 (General Assembly of Brussels 1951 - Snow and Ice), Vol. 1, 185-193.

Hay, J. E. and B. B. Fitzharris. 1988. A comparison of the energy-balance and bulk-aerodynamic approaches for estimating glacier melt. F. Glaciol., 34 (117), $145-153$.

Huybrechts, P., A. Letréguilly and N. Reeh. 1991. The Greenland ice sheet and greenhouse warming. Global and Planetary Change, 3 (4), 399-412.

Konzelmann, T. and R.J. Braithwaite. 1995. Variations of ablation, albedo and energy balance at the margin of the Greenland ice sheet, Kronprins Christian Land, eastern North Greenland. 7. Glaciol., 41 (137), 174-182.

Kreyszig, E. 1970. Introductory mathematical statistics. New York, John Wiley and Sons.

Lliboutry, L. 1974. Multivariate statistical analysis of glacier annual balances. f. Glaciol., 13 69), 371-392.

Müller, F. and C. M. Keeler. 1969. Errors in short-term ablation measurements on melting ice surfaces. J. Glaciol., 8 (52), 91-105.

Munro, D. S. 1990. Comparison of melt energy computations and ablatometer measurements on melting ice and snow. Arct. Alp. Res., 222 $153-162$.

Olesen, O. B. and R. J. Braithwaite. 1989. Field stations for glacier climate research, West Greenland. In Oerlemans, J., ed. Glacier fluctuations and climatic change. Dordrecht, etc., Kluwer Academic Publishers, 207-218.

Reynaud, L., M. Vallon and A. Letréguilly. 1986. Mass-balance measurements: problems and two new methods of determining variations. 7 . Glaciol., $32(112), 446-454$.

Schytt, V. 1962. Mass balance studies in Kebnekajse. J. Glaciol., 4 (33), 281-288.

Streten, N. A. and G. Wendler. 1968. The midsummer heat balance of an Alaskan maritime glacier. f. Glaciol., 7(51), 431-440.

Wendler, G. and G. Weller. 1974. A heat-balance study on McCall Glacier, Brooks Range, Alaska: a contribution to the International Hydrological Decade. f. Glaciol., 13 (67), 13-26. 